\title{
MYH ASSOCIATED POLYPOSIS WITH A p.Tyr165Cys MUTATION IN A MOROCCAN PATIENT
}

\author{
Laarabi FZ ${ }^{1, *}$, Jaouad IC ${ }^{1}$, El Kerch F ${ }^{1}$, Sefiani $\mathrm{A}^{1,2}$
}

*Corresponding Author: Ms. Fatima Zahra Laarabi, Département de Génétique Médicale, Institut National d'Hygiène, 27, Avenue Ibn Battouta, B.P. 769 Rabat, Morocco; Tel.: +212(0)37-77-1902; Fax: 212(0)37-77-20-67; E-mail: fz_laarabi@yahoo.fr

\begin{abstract}
Recessively inherited mutations in the base excision repair gene $M Y H$ are related to $M Y H$-associated polyposis (MAP). We report a Moroccan patient who carried the mutation p.Tyr165Cys. Genetic testing for MYH mutations should have important implications for accurate genetic counseling, and cancer surveillance for patients with colorectal cancers and their family members in Morocco.
\end{abstract}

Key words: Colorectal cancer, MYH gene, p.Tyr165 Cys mutation

\section{INTRODUCTION}

Colorectal cancer is the third most common form of cancer in males and the second most common in females [1]. Although the majority of such cases are sporadic, about a quarter of cases may involve some hereditary predisposition. A small proportion are familial, in which a very strong genetic predisposition to develop colorectal cancer is passed on within affected families. Hereditary non polyposis colorectal cancer (HNPCC) and familial adenomatous polyposis (FAP) are the most common familial forms of colorectal cancer. A small number of FAP

1 Département de Génétique Médicale, Institut National d'Hygiène, Rabat, Morocco

2 Laboratoire de Génomique Humaine, Faculté de Médecine et de Pharmacie, Université Mohamed V, Rabat, Morocco cases involve germline mutations in the $M Y H$ gene, and are sub-grouped as $M Y H$-associated polyposis (MAP) [1].

$\mathrm{MYH}$-associated polyposis is caused by germline mutations in the base excision repair (BER) gene MUTYH (MYH) located on chromosome 1p34.3p32.1, which contains 16 exons. The first description of an affected family was reported in 2002 [2]. The phenotype is often indistinguishable from that of an attenuated autosomal dominant FAP caused by mutations in the APC gene, but in MAP, the number of adenomas is often lower (from five to more than 100 ), and affected patients are often sporadic cases. Two mutational hot-spots have been identified in the $M Y H$ gene, p.Tyr165Cys and p.Gly382Asp [3], corresponding to approximately $90 \%$ of the mutations identified in affected Caucasians [4].

The only mutation reported in two unrelated Moroccan patients living abroad is the c.1186_1187insGG, p.Glu 396fsX42, within exon 13 [2]. We searched for these three mutations in the $M Y H$ gene, in a patient referred to the Department of Medical Genetics in Rabat, Morocco.

Case Report. A 53-year old man, born of non consanguineous healthy parents, was referred to our department for colorectal cancer and genetic counseling. His brothers and sisters are healthy and they never showed any digestive problems. His clinical history started with asthenia related to anemia, which was accompanied by gastric pain, intermittent abdominal colic, and on fibroscopy showed the presence of many polyps. A rectal injection of barium hydroxide in double contrast confirmed multi- 
ples polyps and showed a suspect nodule in the right colon. Pathological examination found the biopsied polyps to be adenocarcinoma of Duke. Some 80 adenomatous polyps were distributed throughout the colon.

Informed consent was obtained for DNA testing according to approved protocols. DNA was extracted from whole blood by standard methods, and the two exons 7 and 13 were amplified by polymerase chain reaction (PCR) and sequenced on an ABI PRISM ${ }^{\mathrm{TM}} 310$ genetic analyzer (Applied Biosystems, Foster City, CA, USA) to detect the p.Tyr165Cys, p.Gly382Asp and c.1186_1187insGG MYH mutations. Any mutation was confirmed on a second independent DNA sample.

\section{RESULTS AND DISCUSSION}

The molecular analysis of the $M Y H$ gene in this patient showed that he carried the p.Tyr165Cys (c.494A $>$ G) mutation in a homozygous state (Figure 1). This is the first association report between colorectal cancer and the MYH mutation p.Tyr165Cys in Morocco.

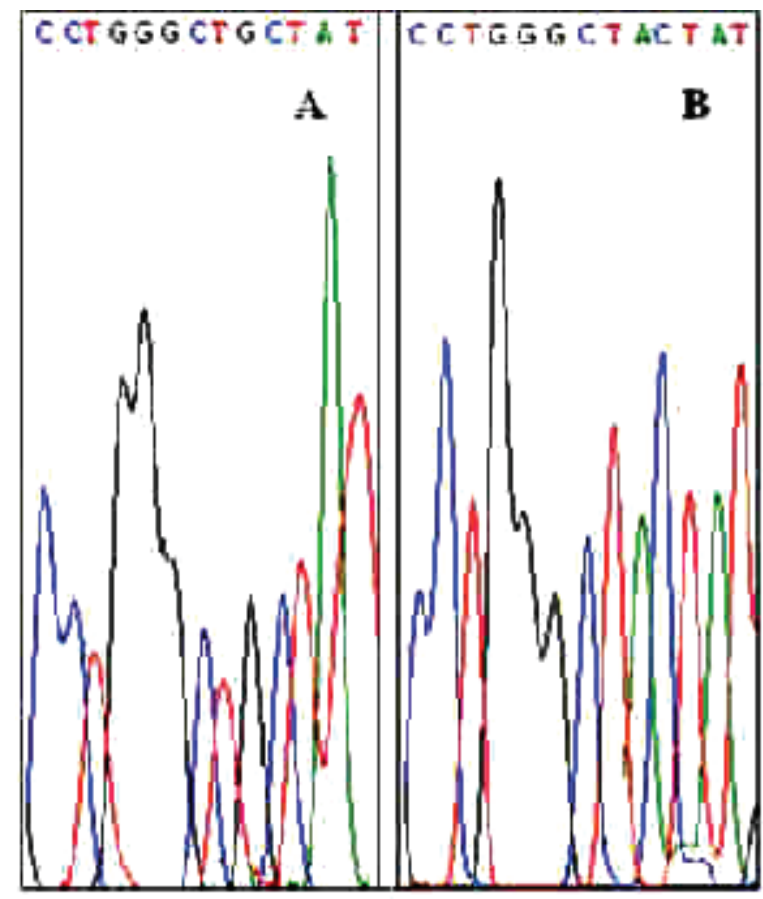

Figure 1. A.Sequence of the patient carrying the mutation c. $494 \mathrm{~A}->\mathrm{G}$ at a homozygous state (Y165C)

B. Normal sequence of the exon 7 of the MYH gene.
Considering the high level of consanguinity in Morocco, screening for MYH mutations should be considered in young patients presenting with sporadic colorectal cancer, even with a limited number of adenomas. A variable number of polyps (ranging from five to 100) and early onset colorectal cancer; absence of vertical transmission from parent to offspring, sporadic or multiple-case presentations within one generation, are characteristic of an autosomal recessive pattern of inheritance [5] and represent a clinical-genetic picture of MAP. This observation is similar to those described in previous studies $[3,6,7]$ and confirms that $M Y H$ mutations are not frequent in the general population [8].

In Morocco, consanguineous marriage is culturally favored and is an integral part of the country's cultural and social life. The high rate of consanguinity $(15.25 \%)$ explains the prevalence of autosomal recessive diseases in the country [9]. Therefore, we expect that MAP may be more common in this country than in developed countries. This consideration should be integrated in any colorectal cancer surveillance program.

In conclusion, patients with a classical or attenuated form of polyposis coli should be screened for MYH mutations. Identification of MYH mutations has important implications for the diagnosis, screening, genetic counseling, follow-up and therapeutic options in patients with colorectal cancer. Gene testing should identify siblings of MAP cases who are at risk and clarify the genetic status of spouses of those with biallelic mutations, so that their offspring can be counseled.

\section{ACKNOWLEDGMENTS}

This study was supported by the National Centre for the Scientific Research and Technique (CNRST). Fatima Zahra Laarabi is a Ph.D. student from the Laboratory of Genetics and Biometrics, Faculty of Science, University Ibn Tofail-Kénitra, Morocco.

\section{REFERENCES}

1. Halford SE, Rowan AJ, Lipton L, Sieber OM, Pack K, Thomas HJ, Hodgson SV, Bodmer WF, Tomlinson IP. Germline mutations but not somatic changes at the MYH locus contribute to the 
pathogenesis of unselected colorectal cancers. Am J Pathol 2003; 162(5): 1545-1548.

2. Nielsen M, Franken PF, Reinards TH, Weiss MM, Wagner A, van der Klift H, Kloosterman S, Houwing-Duistermaat JJ, Aalfs CM, Ausems MG, Bröcker-Vriends AH, Gomez Garcia EB, Hoogerbrugge N, Menko FH, Sijmons RH, Verhoef S, Kuipers EJ, Morreau H, Breuning MH, Tops CM, Wijnen JT, Vasen HF, Fodde R, Hes FJ. Multiplicity in polyp count and extracolonic manifestations in 40 Dutch patients with MYH associated polyposis coli (MAP). J Med Genet 2005; 42(9): e54.

3. Al Tassan N, Chmiel NH, Maynard J, Fleming N, Livingston AL, Williams GT, Hodges AK, Davies DR, David SS, Sampson JR, Cheadle JP. Inherited variants of MYH associated with somatic G:C $>$ T:A mutations in colorectal tumors. Nat Genet 2002; 30(2): 227-232.

4. Cleary SP, Cotterchio M, Jenkins MA, Kim H, Bristow R, Green R, Haile R, Hopper JL, LeMarchand L, Lindor N, Parfrey P, Potter J, Younghusband B, Gallinger S. Germline MutY human homologue mutations and colorectal cancer: a multisite casecontrol study. Gastroenterol 2009; 136(4): 12511260.

5. Avezzù A, Agostini M, Pucciarelli S, Lise M, Urso ED, Mammi I, Maretto I, Enzo MV, Pastrello C,
Lise M, Nitti D, Viel A. The role of MYH gene in genetic predisposition to colorectal cancer: another piece of the puzzle. Cancer Lett 2008; 268(2): 308-313.

6. Jones S, Emmerson P, Maynard J, Best JM, Jordan S, Williams GT, Sampson JR, Cheadle JP. Biallelic germline mutations in MYH predispose to multiple colorectal adenoma and somatic $\mathrm{G}: \mathrm{C}>\mathrm{T}: \mathrm{A}$ mutations. Hum Mol Genet 2002, 11(23): 29612967.

7. Sieber OM, Lipton L, Crabtree M, Heinimann K, Fidalgo P, Phillips RK, Bisgaard ML, Omtoft TF, Aaltonen LA, Hodgson SV, Thomas HJ, Tomlinson IP. Multiple colorectal adenomas, classic adenomatous polyposis, and germ-line mutations in MYH. N Engl J Med 2003, 348(9): 791-799.

8. Isidro G, Laranjeira F, Pires A, Leite J, Regateiro F, Castro E, Soares J, Castro C, Giria J, Brito MJ., Medeira A, Teixeira R, Morna H, Gaspar I, Marinho C, Jorge R, Brehm A, Ramos J.S, Boavida MG. Germline MUTYH (MYH) mutations in Portuguese individuals with multiple colorectal adenomas. Hum Mutat 2004; 24(4): 353-354.

9. Jaouad IC, Elalaoui SC, Sbiti A, Elkerh F, Belmahi L, Sefiani A. Consanguineous marriages in Morocco and the consequence for the incidence of autosomal recessive disorders. J Biosoc Sci 2009; 41(5): 575-581. 